\title{
Correlation between patterns of HIV-I drug resistance and drug administration in antiretroviral experienced patients in Greece during 1999-2006
}

\author{
D Paraskevis*1, G Magiorkinis², E Magiorkinis², V Sypsa², PG Gargalianos³, \\ MC Lazanas ${ }^{4}$, V Paparizos ${ }^{5}$, A Karafoulidou ${ }^{6}$, T Kordossis ${ }^{6}$, A Antoniadou ${ }^{7}$, \\ H Sambatakou $^{8}$, GL Daikos ${ }^{6}$ and A Hatzakis ${ }^{2}$
}

Address: ${ }^{1}$ Medical School, University of Athens, Athens, Greece, ${ }^{2}$ Dept of Hygiene Epidemiology and Medical Statistics, Athens, Greece, ${ }^{3}$ Genimatas Hospital, Athens, Greece, ${ }^{4}$ Red Cross Hospital, Athens, Greece, 5 "A. Syngros" Hospital, Athens, Greece, ${ }^{6 " L a i k o n " ~ G H, ~ A t h e n s, ~ G r e e c e, ~}$ ${ }^{7}$ Attikon University General Hospital, Athens, Greece and " "Ippokrateion" GH, Athens, Greece

* Corresponding author

from Ninth International Congress on Drug Therapy in HIV Infection

Glasgow, UK. 9-13 November 2008

Published: 10 November 2008

Journal of the International AIDS Society 2008, I I (SuppI I):PI86 doi:I0.I I86/I758-2652-I I-SI-PI86

This abstract is available from: http://www.jiasociety.org/content/I I/SI/PI86

(C) 2008 Paraskevis et al; licensee BioMed Central Ltd.

\section{Purpose of the study}

There is a global trend for declining HIV-1 resistance over time in antiretroviral-experienced patients. We aimed to investigate if the decreasing resistance to $\mathrm{N}(\mathrm{t}) \mathrm{RTIs}$ and PIs among the treated patients in Greece during 1999-2006, is correlated with the administration of any particular drugs.

\section{Methods}

HIV-1 genotypic resistance was determined from 1,327 treated patients failing on the first treatment regimen (HIV-RNA $>1000$ copies $/ \mathrm{mL}$ ) later than 1998. All sequences along with a detailed treatment history record were stored in a HIV sequence database. Potential association between the levels of resistance and the percentage of drugs received before resistance testing per year was explored by estimating the slope of change in the proportion of resistant strains over increasing drug use.

\section{Summary of results}

Increased duration of TDF was associated with decreasing levels of resistance $(\mathrm{p}<0.001)$. The slope of change in $\%$ resistance for $10 \%$ increase in drug administration was 0.026. A similar trend was observed also for ABC (slope: $0.078, \mathrm{p}<0.001)$. On the other hand, increased use for
$\mathrm{ZDV}$, 3TC and $\mathrm{d} 4 \mathrm{~T}$ was associated with increasing resistance $(\mathrm{p}<0.001)$. No trend was found for ddI. Decreasing resistance to PIs was associated with boosted PIs such as bLPV (slope: -0.038, p < 0.001), bATV (slope: -0.119 , p < 0.001 ) and bTPV (slope: $-0,126, \mathrm{p}<0.001$ ), but not for bSQV(slope:0.62, $\mathrm{p}<0.001$ ). Similarly elevating resistance was correlated with increased use for IDV (slope: 0.051, p < 0.001), SQV (slope: 0.093, p < 0.001), RTV (slope: 0.074, $\mathrm{p}<0.001$ ) and NLF (slope: 0.036, $\mathrm{p}=$ 0.019 ).

\section{Conclusion}

Patterns of resistance over time are correlated in a different way with the administration of particular drugs. Importantly, ABC, TDF and boosted PIs (bLPV, bATV and bTPV) are associated with decreasing resistance to $\mathrm{N}(\mathrm{t}) \mathrm{RTIs}$ and PIs during 1999-2006. 